\title{
Atividade Antibacteriana do Extrato Etanólico Bruto da Gossypium hirsutum L. contra Cepas de Klebsiella pneumoniae e Escherichia coli
}

\author{
Antibacterial activity of Gossypium hirsutum L. crude ethanol extract against strains of \\ Klebsiella pneumoniae and Escherichia coli
}

\begin{abstract}
Actividad Antibacteriana del Extracto Etanólico Bruto de la Gossypium hirsutum L. contra Cepas de Klebsiella pneumoniae y Escherichia coli
\end{abstract}

Letícia Ataíde Delgado ${ }^{1}$, Daniele de Sousa Siqueira', José Lucas Soares Ferreira ${ }^{1}$, Joyce Natielle Miranda Cavalcante ${ }^{1}$, Rebeca Cícera Mendes de Oliveira Silva ${ }^{1}$, Rafael Cartaxo Filgueira' ${ }^{1}$, Raquel Vieira Bezerra ${ }^{1}$, Heloisa Mara Batista Fernandes de Oliveira² ${ }^{2}$ Maria das Graças Veloso Marinho de Almeida $^{3}$, Abrahão Alves de Oliveira Filho ${ }^{4 *}$.

\section{RESUMO}

Objetivo: O presente estudo objetiva avaliar in vitro a ação antibacteriana do extrato da G. hirsutum L. contra Escherichia coli e Klebsiella pneumoniae. Métodos: Para a avaliação da atividade antibacteriana e determinação da Concentração Inibitória Mínima (CIM) utilizou-se a técnica de microdiluição em placa de 96 poços. Em uma placa de 96 cavidades, foi adicionado caldo Mueller Hinton e o extrato etanólico bruto em estudo nas diferentes concentrações. $O$ ensaio foi realizado em duplicata. As placas foram incubadas a $37^{\circ} \mathrm{C}$ durante 24-48 horas. A CIM foi determinada como a menor concentração do extrato que inibir o crescimento visível do microorganismo. Após a leitura da CIM, alíquotas de $20 \mu \mathrm{L}$ foram retiradas de cada poço que não apresentar crescimento bacteriano, e transferidas para poços de uma nova placa, desprovidas de qualquer antimicrobiano. As placas inoculadas foram assepticamente fechadas e incubadas a $35{ }^{\circ} \mathrm{C}$, e as Concentrações Bactericidas Mínimas (CBMs) foram registradas após $48 \mathrm{~h}$. A CBM foi definida como a menor concentração do extrato que resultar em inibição visível do crescimento do microorganismo. Resultados: Observou-se que o extrato em estudo apresentou $\mathrm{CIM}_{50}$ para $E$. coli e K. pneumoniae, respectivamente, igual à $1024 \mu \mathrm{g} / \mathrm{mL}$ e maior que $1024 \mu \mathrm{g} / \mathrm{mL}$ e a CBM So $_{0}$ da $E$. coli foi maior que $1024 \mu \mathrm{g} / \mathrm{mL}$. Conclusão: Diante dos resultados obtidos pode-se afirmar que o extrato possui efeito moderado antibacteriano frente às cepas de K. peneumoniae e E. coli.

Palavras-chave: Microbiologia, Farmacologia, Fitoterapia.

\begin{abstract}
Objective: The present study aims to evaluate the antibacterial action of the extract of $\mathrm{G}$. hirsutum L. against Escherichia coli and Klebsiella pneumoniae. Methods: For the evaluation of the antibacterial activity and determination of MIC, the 96-well plate microdilution technique is used. In a 96-well plate, Mueller Hinton broth and the crude ethanolic extract under study at different concentrations. The assay was performed in duplicate. The plates were incubated at $37^{\circ} \mathrm{C}$ for 24-48 hours. The Minimum Inhibitory Concentration (MIC) was determined as the lowest concentration of the extract that inhibited the visible growth of the microorganism. After reading the MIC, aliquots of $20 \mu \mathrm{L}$ were withdrawn from each well that did not show bacterial growth, and transferred to wells of a new plaque, devoid of any antimicrobial. The inoculated plates were aseptically closed

\footnotetext{
${ }^{1}$ Universidade Federal de Campina Grande - Patos, Paraíba, Brasil.

2 Universidade Federal do Rio Grande do Norte- Santa Cruz-Rio Grande do Norte, Brasil.

3 Professora Doutora, do curso de Ciências Biológicas da Universidade Federal de Campina Grande

${ }^{4}$ Professor Doutor, do curso de Odontologia da Universidade Federal de Campina Grande.

*E-mail: abrahao.farm@gmail.com
} 
and incubated at $35^{\circ} \mathrm{C}$, and the Minimum Bactericidal Concentrations (MBCs) were recorded after $48 \mathrm{~h}$. MBC was defined as the lowest extract concentration that results in visible inhibition of microorganism growth. Results: It was observed that the extract under study had MIC of $1024 \mu \mathrm{g} / \mathrm{mL}$ and MBC50 greater than 1024 $\mu \mathrm{g} / \mathrm{mL}$. Conclusion: In view of the obtained results it can be affirmed that the extract has a moderate antibacterial effect against the strains of K. pneumoniae and E. coli.

Keywords: Microbiology, Farmacology, Phytotherapy.

\section{RESUMEN}

Objetivo: El presente studio objetiva evaluar in vitro la acción antibacteriana del extracto de G. hirsutum L. contra Escherichia coli y Klebsiella peneumoniae. Métodos: Para la evaluación de la actividad antibacteriana y determinación de la CIM se utilizó la técnica de microdilución en placa de 96 pocillos. En una placa de 96 cavidades, se añadió caldo Mueller Hinton y el extracto etanólico bruto en estudio, en las diferentes concentraciones. El ensayo se realizó en duplicado. Las placas fueron incubadas a 37으 durante 24-48 horas. La Concentración Mínima de Inhibición (CIM) fue determinada como la menor concentración del extracto que inhibe el crecimiento visible del microorganismo. Después de la lectura de la CIM, alícuotas de $20 \mu l$ fueron retiradas de cada pocillo que no presentar crecimiento bacteriano, y transferidas a pozos de una nueva placa, desprovistas de cualquier antimicrobiano. Las placas inoculadas se cerraron e incubadas a $35^{\circ} \mathrm{C}$, y las Concentraciones Bactericidas Mínimas (CBM) se registraron después de 48 h. La CBM fue definida como la menor concentración del extracto que resultó en inhibición visible del crecimiento del microorganismo. Resultados: Se observó que el extracto en estudio presentó CIM50 para E. coli y K. pneumoniae, respectivamente, igual a $1024 \mu \mathrm{g} / \mathrm{ml}$ y mayor que $1024 \mu \mathrm{g} / \mathrm{ml}$ y la CBM50 de E. coli fue mayor que $1024 \mu \mathrm{g} /$ $\mathrm{ml}$. Conclusión: Ante los resultados obtenidos se puede afirmar que el extracto tiene efecto moderado antibacteriano frente a las cepas de K. peneumoniae y E. coli.

Palabras clave: Microbiología, Farmacología, Fitoterapia.

\section{INTRODUÇÃO}

Plantas da Familia Malvaceae, a qual pertence a Gossypium hirsutum L., são usadas em comunidades ribeirinhas do município de Manacapurú, Amazonas, no tratamento de inflamações, pneumonia, cólica, tosse e gastrites (VASQUEZ et al.,2014).

Muitas espécies da família Malvaceae estão em estudo, diante do intenso uso da população, podem ser consideradas com grande potencial fitoterápico. Dentre os 250 gêneros e 4200 espécies encontradas nessa família, encontramos aproximadamente 80 gêneros e 400 espécies em solos brasileiros (AGEITEC, 2002).

Gossypium hirsutum L. conhecida como algodão pertence à família Malvaceae é cultivada principalmente para fornecimento de matéria prima para fins industriais. No Brasil a literatura etnofarmacológica refere seu uso na forma de chá, preparado com as folhas no tratamento de disenteria, hemorragia uterina e também, o emprego local das folhas como cicatrizante (LORENZI e MATOS, 2002).

Testes fitoquímicos na Gossypium hirsutum L. constataram a presença de metabólitos secundários como alcaloides, cumarinas, saponinas, flavanoides, triterpenos e taninos, que podem estar relacionados com a atividade antibacteriana frente à Staphylococus aureus e Escherichia coli (MIRANDA et al., 2013).

Klebsiella pneumoniae é um bacilo Gram-negativo da família Enterobacteriaceae, podendo ser encontrada em trato respiratório alto e trato gastro-intestinal e urinário, causando pneumonia lobar e infecção urinária e septicemia. É uma das bactérias mais comumente encontradas em todo o mundo, sendo comum em casos de infecção do trato respiratório. Tem sido reconhecida como um patógeno pulmonar, desde a sua descoberta, há mais de 100 anos (KO et al., 2002).

Carvalho et al. (2017) sugerem relação entre a pneumonia nosocomial, que tem como causa a Klebsiella pneumoniae, e a doença periodontal, uma vez que a infecção bacteriana em pacientes com periodontite pode 
favorecer a colonização da orofaringe, perpetuando a infecção através de mediadores inflamatórios e imunológicos, facilitando assim a colonização por patógenos bucais e repiratórios nos tecidos pulmonares.

A Escherichia colié um bacilo Gram-negativo, anaeróbio facultativo, de oxidase negativa, catalase positiva, fermentador de lactose, sacarose e glicose, pode apresentar motilidade. Esta espécie pode ser patogênica ao homem e outros animais, ocasionando desde doenças no trato gastrointestinal até o óbito (YNGST et al., 2006; DWORKIN, FALKOW, ROSENBERG et al., 2006).

Sendo assim, este artigo tem como objetivo Avaliar o potencial antimicrobiano do extrato etanólico bruto da Gossypium hirsutum L. contra contra Cepas de Klebsiella pneumoniae e Escherichia coli.

\section{MÉTODOS}

\section{Ensaios in vitro}

\section{Substâncias-teste}

O extrato etanólico bruto da Gossypium hirsutum foi cedido pela professora Dra. Maria das Graças Veloso Marinho da Universidade Federal de Campina Grande. Para a realização dos ensaios farmacológicos, as substâncias foram solubilizadas em DMSO e diluída em água destilada. A concentração de DMSO (dimetilsulfóxido) utilizada foi inferior a $0,1 \% \mathrm{v} / \mathrm{v}$. O antimicrobiano utilizado na execução dos testes como controle positivo foi o cloranfenicol, adquirido da Sigma-Aldrich ${ }^{\circledR}$ (São Paulo-SP).

\section{Espécies Bacterianas e Meio de cultura}

Foram utilizadas bactérias Gram-negativas sendo elas: Escherichia coli ATCC 8539, Escherichia coli 101, Escherichia coli 102, Escherichia coli 103, Escherichia coli 104, Klebsiella pneumoniae ATCC 13883, Klebsiela pneumoniae 101, Klebsiela pneumoniae 104, Klebsiela pneumoniae 105, provenientes do Laboratório de Microbiologia da Unidade Acadêmica de Ciências Biológicas do Centro de Saúde e Tecnologia Rural da Universidade Federal de Campina Grande, campus Patos, Paraíba.

Todas as cepas se mantiveram em meio ágar Muller Hinton a uma temperatura de $4{ }^{\circ} \mathrm{C}$, sendo utilizados para os ensaios repiques de 24 horas em Àgar Muller Hinton incubados a $35^{\circ} \mathrm{C}$. No estudo da atividade antimicrobiana será utilizado um inóculo bacteriano de aproximadamente $1,5 \times 10^{8} \mathrm{UFC} / \mathrm{mL}$ padronizado de acordo com a turbidez do tubo 0,5 da escala de McFarland (CLEELAND e SQUIRES, 1991; HADACEK e GREGER, 2000).

\section{Determinação da Concentração Inibitória Mínima (CIM)}

A concentração inibitória mínima foi determinada pela técnica de microdiluição em caldo (CLEELAND e SQUIRES, 1991; HADACEK e GREGER, 2000). Foram utilizadas placas de 96 wells estéreis e com tampa. Em cada well da placa, é adicionado $100 \mu \mathrm{L}$ do meio líquido caldo Mueller Hinton duplamente concentrado. Em seguida, $100 \mu \mathrm{L}$ da emulsão do extrato na concentração inicial de $1024 \mu \mathrm{g} / \mathrm{mL}$ (também duplamente concentrado), foram dispensados nas cavidades da primeira linha da placa. E por meio de uma diluição seriada em razão de dois, obtiveram-se as concentrações de 1024, 512, 256, 128, 64, 32, 16, 8 e $4 \mu \mathrm{g} / \mathrm{mL}$, de modo que na primeira linha da placa encontra-se a maior concentração e na última, a menor concentração. Por fim, foi adicionou-se $10 \mu \mathrm{L}$ do inóculo de aproximadamente $1,5 \times 10^{8} \mathrm{UFC} / \mathrm{mL}$ das espécies bacterianas nas cavidades, onde cada coluna da placa refere-se a uma cepa de bactéria, especificamente.

Paralelamente, foi feito o controle positivo com o antibacteriano cloranfenicol. Um controle de microorganismo foi realizado colocando-se nas cavidades $100 \mu \mathrm{L}$ do mesmo caldo Mueller Hinton duplamente concentrado, $100 \mu \mathrm{L}$ de água destilada estéril e $10 \mu \mathrm{L}$ do inóculo de cada espécie. Para verificar a ausência de interferência nos resultados pelos solventes utilizados na preparação da emulsão, no caso o DMSO, realizou-se um controle no qual foram colocados nas cavidades $100 \mu \mathrm{L}$ do caldo duplamente concentrado, $100 \mu \mathrm{L}$ de DMSO e $10 \mu \mathrm{L}$ da suspensão bacteriana. Um controle de esterilidade do meio também foi realizado, onde colocou-se $200 \mu \mathrm{L}$ do caldo Mueller Hinton em um orifício sem a suspensão das bactérias. 
As placas foram assepticamente fechadas e incubadas a $35^{\circ} \mathrm{C}$ por 24 - 48 horas para ser realizada a leitura. A CIM para o extrato e o antibacteriano foi definida como a menor concentração capaz de inibir visualmente o crescimento bacteriano verificado nos orifícios quando comparado com o crescimento controle. Os experimentos foram realizados em duplicata.

\section{Determinação da Concentração Bactericida Mínima (CBM)}

A concentração bactericida mínima (CBM) também foi determinada para as cepas de bactérias. Após a leitura da CIM em 48 horas, alíquotas de $20 \mu \mathrm{L}$ foram retiradas de cada poço da placa de microtitulação que não apresentaram crescimento bacteriano, e transferidas para poços de uma nova placa de microtitulação contendo $100 \mu \mathrm{L}$ de caldo Mueller Hinton, desprovidas de qualquer antimicrobiano. As placas inoculadas foram assepticamente fechadas e incubadas a $35^{\circ} \mathrm{C}$, e as CBMs foram registradas após $48 \mathrm{~h}$. A CBM é definida como a menor concentração do extrato que resultar em inibição visível do crescimento do microorganismo (PALOMINO et. al, 2002; MANN, MARKHAM, 1998).

\section{RESULTADOS E DISCUSSÃO}

A Concentração Inibitória Mínima (CIM) em meio líquido foi determinada para o extrato etanólico bruto da G. hirsutum L. nas diferentes concentrações explicitadas na metodologia e determinada pela menor concentração capaz de inibir visualmente o crescimento bacteriano, conforme apresentado nas Tabelas 1 e 2. Observou-se que os resultados do extrato para a maioria das cepas foram maiores que $1024 \mu \mathrm{g} / \mathrm{mL}$.

A Concentração Bactericida Mínima (CBM) foi determinada a partir da menor concentração do extrato que resultou em inibição visível do crescimento do microorganismo. De acordo com as Tabelas 1 e 2, observa-se que nenhuma cepa obteve valores iguais ou menor que $1024 \mathrm{ug} / \mathrm{ml}$. Constatando resultado bacteriostático negativo para as concentrações estudadas.

Tabela 1 - Concentração inibitória mínima (CIM) e Concentração bactericida mínima (CBM) em $\mu \mathrm{g} / \mathrm{mL}$ do extrato etanólico bruto da G. hirsutum L. contra diferentes cepas de E. coli.

\begin{tabular}{ccc}
\hline Cepas E. coli & CIM $(\mu \mathrm{g} / \mathrm{mL})$ & CBM $(\mu \mathrm{g} / \mathrm{mL})$ \\
\hline ATCC 8539 & - & - \\
Ec 101 & 1024 & - \\
Ec 102 & - & - \\
Ec 103 & - & - \\
Ec 104 & 1024 & - \\
\hline
\end{tabular}

(-) Concentrações maiores que $1024 \mu \mathrm{g} / \mathrm{mL}$, não avaliadas neste estudo. Fonte: autoria própria

Tabela 2 - Concentração inibitória mínima (CIM) e Concentração bactericida mínima (CBM) em $\mu \mathrm{g} / \mathrm{mL}$ do extrato etanólico bruto da G. hirsutum L. contra diferentes cepas de K. pneumoniae.
Cepas K. penumoniae
$\operatorname{CIM}(\mu \mathrm{g} / \mathrm{mL})$
CBM $(\mu \mathrm{g} / \mathrm{mL})$

\section{K. pneumoniae ATCC 13883}

K. pneumoniae 101

1024

K. pneumoniae 104

K. pneumoniae 105

(-) Concentrações maiores que $1024 \mu \mathrm{g} / \mathrm{mL}$, não avaliadas neste estudo. Fonte: autoria própria., 
Testes fitoquímicos na Gossypium hirsutum L. constataram a presença de metabólitos secundários, compostos fenólicos, flavonoides, taninos, triterpenos, e esteróides que podem estar relacionados com a atividade antibacteriana frente à Staphylococus aureus e Escherichia coli. (MIRANDA et al., 2013). Flavanoides são bastante conhecidos pela forte atividade antioxidante, antiinflamatória e antimicrobiana dos compostos que a constituem. Triterpenos também possuem atividade antibacteriana, além da atividade inseticida. (WESTON, MATHESIUS, 2013; CIMANGA, KAMBU, TONA, et al, 2002)

Segundo Sartoratto et al.(2004), os valores entre $50-500 \mu \mathrm{g} / \mathrm{ml}$ tem uma forte atividade, $600-1500 \mu \mathrm{g} / \mathrm{ml}$ tem uma moderada atividade e os valores acima de $1500 \mu \mathrm{g} / \mathrm{ml}$ tem uma fraca atividade antibacteriana. Com isso, o extrato etanólico da Gossypium hirsutum $\mathrm{L}$. apresenta um poder inibitório de crescimento contra E. coli e K. pneumoniae considerado como moderado, pois para ambas as bactérias, o valor da $\mathrm{CIM}_{50}$ (Concentração Inibitória Mínima capaz de inibir 50\% das cepas) foi maior que $1024 \mu \mathrm{g} / \mathrm{mL}$.

Conforme Hafidh et al. (2011), para que um composto seja considerado bactericida ou bacteriostático de acordo com a Concentração Bactericida Mínima (CBM), esta deve ser igual ou duas vezes mais que a CIM ou a CBM deve ser maior que duas vezes a CIM, respectivamente. Analisando os resultados da CBM podese ver que o extrato da $G$. hirsutum L. não possui atividade bactericida contra espécies de $E$. coli e $K$. pneumoniae, nas concentrações estudadas, pois ambas CBM50 (Concentração Bactericida Mínima capaz de inibir $50 \%$ das cepas) foram maior do que $1024 \mu \mathrm{g} / \mathrm{mL}$ frente às cepas.

Bouzada et al. (2009), constatou resultado contra as bactérias $K$. pneumoniae e da $E$. coli com o extrato metanólico da G. hirsutum L, em concentrações maior que $1000 \mu \mathrm{g} / \mathrm{mL}$. Já Miranda et al. (2013), constatou resultado negativo em diferentes graduações alcoólicas do extrato da G. hirtutum L., contra E. coli.

Thian, Zang, Yang, et al, 2017, mostram o extrato das folhas da Abutilon theophrasti, também pertencente à família malvaceae, como alternativa antibiótica, uma vez que apresentou atividade bacteriana significativa contra Escherichia coli e Staphylococcus aureus, tanto entre cepas padrão como em cepas clínicas isoladas.

Ajayi, Jonathan, Adewuy et al (2008) encontraram resultado bastante positivo na ação antibacteriana do óleo essencial da G. hirsutum L. contra a Klebsiella pneumoniae. Omojasola, Awe (2004), constatou atividade antibacteriana do extrato das folhas de Anacardium occidentale e da Gossypium hirsutum I. contra Staphylococcus aureus, E. coli e P. aeruginosa.

\section{CONCLUSÃO}

Diante dos resultados obtidos, observou-se um moderado potencial antibacteriano do extrato etanólico bruto da G. hirsutum L. contra a Escherichia coli e um fraco potencial antibacteriano contra a Klebsiella peneumoniae, auxiliando futuramente no controle da resistência das bactérias aos antimicrobianos já existentes. No entanto, mais estudos são necessários para elucidar o mecanismo de ação deste extrato.

\section{REFERÊNCIAS}

1. AGEITEC. 2002. Agência de Informações Embrapa: Espécies Abóreas Brasileiras. Malvacea. Disponível em: http://www.agencia.cnptia.embrapa.br/gestor/especies_arboreas_brasileiras/arvoreCONT000f. Acesso em: fev. 2018.

2. BOUZADA, ML, FABRI RL, NOGUEIRA M, et al. Antibacterial, cytotoxic and phytochemical screening of some traditional medicinal plants in Brazil. Pharmaceutical biology, 2009; 47(1):44-52

3. CARVALHO PA, ROTBLAND M, NOGUEIRA ACO et al. A doença periodontal como fator de risco para a pneumonia nosocomial. International Journal of Science Dentistry, 2017; 48.

4. CLEELAND R, SQUIRES E. Evalution of new antimicrobials in vitro and in experimental animal infections. In: Lorian, V. M. D. Antibiotics in Laboratory Medicine. New York: Willians \& Wilkins, 1991; 739-788.

5. HADACEK F, GREGER $\mathrm{H}$. Testing of antifungal natural products: methodologies, comparatibility of results and assay choice. Phytochemical Analyses, 2000; 11: 137-147. 
6. HAFIDH RR, ABDULAMIR AS, VERN LS et al. Inhibition of growth of highly resistant bacterial and fungal pathogens by a natural product. Open Microbiol J, 2011; 5: 96-106.

7. KO WC, PATERSON DL, SAGNIMENI AJ et al. Community-Acquired Klebsiella pneumoniae Bacteremia: Global Differences in Clinical Patterns. Emerging Infectious Diseases, 2002; 8(2): 160-166.

8. LEONARDO MR, SILVA RAB, ASSED S et al. Importance of Bacterial endotoxin (LPS), Endodontics. Journal Appl Oral Science, 2004; 12(2): 93.

9. LORENZI H, MATOS FJA. Plantas Medicinais no Brasil: nativas e exóticas. 2nd ed. Nova Odessa, São Paulo: Instituto Plantarum, 2002; 512 .

10. MAEKAWA LE, VALERA MC, Olimveira LDD et al. In vitro evaluation of the action of irrigating solutions associated with intracanal medications on Escherichia coli and its endotoxin in root canals. Journal of Applied Oral Science, 2011; 19(2): 106-112.

11. MANN, CM, MARKHAM, JL. A new method for determining the minimum inhibitory concentration of essential oils. Journal Of Applied Microbiology. 1998; 84(9): 538-544. 1998.

12. MIRANDA, GS, SANTANA, GS, MACHADO, BB. et al, In vitro antibacterial activity of four plant species at diferent alcoholic contentes. Revista Brasileira de Plantas Medicinais, 2013; 25(1): 104-111

13. PALOMINO, JC, MARTIN, A., CAMACHO, M., GUERRA, H., SWINGS, J., PORTALES, F. Resazurin micrtotiter assay plate: simple and inexpensive method for detection of drug resitence Mycrobacterium tuberculosis. Antimicrobial Agents and Chemoterapy. 2002; 46(8): 2720-2722.

14. WESTON LA, MATHESIUS U, 2013. Flavonoids: their structure, biosynthesis and role in the rhizosphere, including allelopathy. Journal of Chemical Ecology. 2013; 39(2): 283- 297.

15. CIMANGA K, KAMBU K, TONA L, et al. Correlation between chemical composition and antibacterial activity of essential oils of some aromatic medicinal plants growing in the Democratic Republic of Congo. J Ethnopharmacol, 2002; 79: 213-220.

16. SARTORATTO A, MACHADO A, DELARMELINA C et al. Composition and antimicrobial activity of essential oils from aromatic plants used in Brazil. Brazilian Journal of Microbiology, 2004; 35(4): 275-280.

17. TRABULSI LR, ALTERTHUM F. Microbiologia. 6nd ed. São Paulo: Atheneu, 2015.

18. VÁSQUEZ SPF, MENDONÇA MS, NODA SN et al. Etnobotânica de plantas medicinais em comunidades ribeirinhas do Município de Manacapuru, Amazonas, Brasil. Acta Amazonica, 2014; 44(4): 457-472.

19. DWORKIN M, FALKOW S, ROSENBERG E et al. The prokaryotes: A Handbook on the Biology of Bacteria. 3nd ed. New York: Springer-verlag New York, 2006; 6.

20. YNGST SL, SAAD MD, FELT AS et al. Classifyng Escherichia coli. Emerging Infectious Disseases, 2006; 12(8): 1297-1298.

21. TIAN C, ZHANG D, YANG C, et al. RESEARCH ON EXTRACTION TECHNOLOGY, ANTIBACTERIAL AND ANTIOXIDANT ACTIVITY OF ETHANOL EXTRACT FROM LEAVES OF ABUTILON THEOPHRASTI MEDIC. Acta Poloniae Pharmaceutica ñ Drug Research, 2017; 74 (3):881-890

22. Ajayi IA, Jonathan SG, Adewuyi A et al, Antimicrobial Screening of the Essential Oil of Some Herbal Plants from Western Nigeria, World Applied Sciences Journal, 2008; 3(1): 79-81

23. OMOJASOLA PF, AWE S. The antibacterial activity of the leaf extracts of Anacardium occidentale and Gossypium inisutum against some selected microorganisms. Biosci. Res. Comm. 2004; 16:25-28 